\title{
Arterial stiffness, central hemodynamics, and cardiovascular risk in hypertension
}

\author{
This article was published in the following Dove Press journal: \\ Vascular Health and Risk Management \\ 6 December 201I \\ Number of times this article has been viewed
}

\author{
Paolo Palatini' \\ Edoardo Casiglia' \\ Jerzy Gąsowski² \\ Jerzy Głuszek ${ }^{3}$ \\ Piotr Jankowski ${ }^{4}$ \\ Krzysztof Narkiewicz ${ }^{5}$ \\ Francesca Saladini' \\ Katarzyna Stolarz-Skrzypek ${ }^{4}$ \\ Valérie Tikhonoff' \\ Luc Van Bortel ${ }^{6}$ \\ Wiktoria Wojciechowska ${ }^{4}$ \\ Kalina Kawecka-Jaszcz ${ }^{4}$ \\ 'Department of Clinical and \\ Experimental Medicine, University of \\ Padova, Padua, Italy; ${ }^{2}$ Department of \\ Internal Medicine and Gerontology, \\ Jagiellonian University Medical \\ College, Kraków, Poland; ${ }^{3}$ Department \\ of Arterial Hypertension, University \\ Hospital, Poznań, Poland; ${ }^{4}$ First \\ Department of Cardiology and \\ Hypertension, Jagiellonian University \\ Medical College, Kraków, Poland; \\ ${ }^{5}$ Department of Hypertension and \\ Diabetology, Medical University of \\ Gdansk, Gdansk, Poland; ' ${ }^{6}$ eymans \\ Institute of Pharmacology, Ghent \\ University, Ghent, Belgium
}

\begin{abstract}
This review summarizes several scientific contributions at the recent Satellite Symposium of the European Society of Hypertension, held in Milan, Italy. Arterial stiffening and its hemodynamic consequences can be easily and reliably measured using a range of noninvasive techniques. However, like blood pressure (BP) measurements, arterial stiffness should be measured carefully under standardized patient conditions. Carotid-femoral pulse wave velocity has been proposed as the gold standard for arterial stiffness measurement and is a well recognized predictor of adverse cardiovascular outcome. Systolic BP and pulse pressure in the ascending aorta may be lower than pressures measured in the upper limb, especially in young individuals. A number of studies suggest closer correlation of end-organ damage with central BP than with peripheral BP, and central BP may provide additional prognostic information regarding cardiovascular risk. Moreover, BP-lowering drugs can have differential effects on central aortic pressures and hemodynamics compared with brachial BP. This may explain the greater beneficial effect provided by newer antihypertensive drugs beyond peripheral BP reduction. Although many methodological problems still hinder the wide clinical application of parameters of arterial stiffness, these will likely contribute to cardiovascular assessment and management in future clinical practice. Each of the abovementioned parameters reflects a different characteristic of the atherosclerotic process, involving functional and/or morphological changes in the vessel wall. Therefore, acquiring simultaneous measurements of different parameters of vascular function and structure could theoretically enhance the power to improve risk stratification. Continuous technological effort is necessary to refine our methods of investigation in order to detect early arterial abnormalities. Arterial stiffness and its consequences represent the great challenge of the twenty-first century for affluent countries, and "de-stiffening" will be the goal of the next decades.
\end{abstract}

Keywords: arterial elasticity, stiffness, compliance, central blood pressure, pulse wave velocity

\section{Introduction}

Interpretation of the arterial pulse has been an important part of the medical examination from ancient times. The arterial pulse was familiar to Chinese, Indian, Greek, and Roman physicians who exploited it regularly in the diagnosis of disease. Galen, a Greek doctor who lived in the second century BC, wrote a book entitled "On Prognosis from the Pulse" in which he described 27 varieties of pulses. Modern understanding of the cardiovascular system and systematic study of the pulse started in the sixteenth century when Józef Struś, a Polish scholar and humanist, published the book "Sphygmicae artis iam mille ducentos annos perditae et desideratae Libri V.' Józef Struś was born in 1510 in Poznań, started his studies in the Faculty of Philosophy at Jagiellonian University in
Correspondence: Paolo Palatini Department of Clinical and Experimental Medicine, University of Padova, Via Giustiniani 2, 35128 Padova, Italy

Tel +390498212278

Fax +390498754179

Email palatini@unipd.it 
Cracow, and then studied at the College of Medicine and Philosophy in Padua from 1532 to 1537 . In the second half of 1537, Józef Struś returned to Cracow University. Renaissance medicine, similar to medieval medicine, was based on the teachings of Galen. The impressive and logically structured medical knowledge in Galen's works (albeit containing many errors) brought the less critical medieval minds to the belief that whatever Galen had said was indisputable and could not be questioned. Struś emphasized the practical benefits derived from measuring a patient's pulse. In his masterpiece published in Basel in 1555, Józef Struś discussed the types of pulse and their clinical significance. The large number of pulse types described in his book reflects the better powers of observation by doctors of that time, which has been replaced today by instruments. Despite the fact that Struś attached great importance to pulse analysis as a diagnostic method, on numerous occasions he warned against relying solely on it for diagnosis, emphasizing the need for an inquisitive medical interview and a thorough examination of the patient. A rational approach to all the medical problems he dealt with enabled him to record a pulse using curves analogous to those recorded today using a sphygmograph. ${ }^{1}$ True graphic methods for pulse wave recording were introduced much later in the nineteenth century by Marey in Paris and by Mahomed in London. ${ }^{2}$ The velocity waveforms they presented look surprisingly similar, given the relative crudity of the methods employed, to the waveforms obtained by the most modern technology. It is the studies by Struś and many other outstanding scholars who followed in his footsteps that made it possible to start the modern era of arterial mechanics.

Arterial stiffness and its hemodynamic consequences are now established as predictors of adverse cardiovascular outcome. Arterial stiffness is positively associated with systolic hypertension, coronary artery disease, stroke, and heart failure, which are the leading causes of mortality in developed countries. Several measures of arterial stiffness have been employed, which proved useful as predictors of disease in longitudinal studies ${ }^{3-22}$ (Table 1). Among these, pulse wave velocity (PWV) is the parameter which has gained the most attention, and its predictive accuracy has been demonstrated in a number of studies. ${ }^{3-11,21}$

\section{Assessment of pulse wave velocity}

There are two major wall properties of the artery as a whole, ie, arterial stiffness and compliance. These properties depend on both arterial structural organization and intrinsic wall properties, ie, the elastic modulus. Arterial compliance is defined as the change in arterial volume per unit of pressure and reflects the buffering capacity of the arterial wall. Arterial distensibility, the inverse of arterial stiffness, is defined as the relative change in volume per unit of pressure. Arterial compliance depends on arterial stiffness and arterial volume (diameter of the vessel) and is determined by different factors, the three major determinants being mean arterial pressure (MAP), age, and gender. Arterial stiffness increases from the central aorta to the peripheral arteries. ${ }^{23}$ In addition, only these elastic arteries, and not muscular arteries, have been shown to be predictive of cardiovascular morbidity and mortality. ${ }^{23,24}$ Several noninvasive methods are currently used to assess vascular stiffness. PWV and the augmentation index (AI) are the two major noninvasive methods of assessing arterial stiffness. Because some studies suggest that the predictive value of aortic stiffness may be slightly better than carotid artery stiffness, and because of the ease of measurement, aortic (carotid-femoral) PWV has been proposed as the gold standard for arterial stiffness measurement. ${ }^{23-25}$

Like blood pressure (BP) measurements, arterial stiffness should be measured under standardized patient conditions. ${ }^{26}$ It should be performed after at least 10 minutes of supine rest in a quiet room with stable room temperature. No meals, caffeine, or smoking are allowed for 3 hours beforehand, and talking is not allowed during the measurements. Because respiration can be of influence, measurements should be the average of all cardiac cycles within at least one respiratory cycle. ${ }^{26}$ As for BP measurements, one should also be aware of possible white coat effects and diurnal variations in arterial stiffness. To limit variability from the latter, repeated measures done at the same time of the day are advised. Aortic PWV is calculated by dividing the distance travelled by the time travelled. The large majority of devices accurately measure time travelled directly by measuring the time difference between the arrival of the pulse wave at the femoral and carotid arteries, or indirectly by subtracting time from the top of the $\mathrm{R}$ wave of the electrocardiogram to arrival of the pulse wave at the femoral artery minus time from the top of the $\mathrm{R}$ wave of the electrocardiogram to pulse wave arrival at the carotid artery. The distance travelled is estimated mainly by tape measure. Different distance estimates have been proposed. The two most frequently used are the direct distance from the carotid to femoral artery and the subtracted distance, subtracting the distance between the sternal notch to the carotid artery from the sternal notch to the femoral artery. Conversion equations between these two distances have been proposed. ${ }^{27}$ A recent study comparing these tape measure distances with the travelled length measured with magnetic resonance imaging showed that 
Table I Studies reporting independent associations between parameters of arterial stiffness and outcome variables

\begin{tabular}{|c|c|c|c|c|c|}
\hline $\begin{array}{l}\text { Principal } \\
\text { investigator }\end{array}$ & Predictor & Clinical setting (n) & Age (years) & Outcome variables & Relative risk $(95 \% \mathrm{CI})$ \\
\hline \multirow[t]{2}{*}{ Blacher et $\mathrm{al}^{3}$} & PWV & ESRD (24I) & 51 & CV mortality & OR $5.9(95 \% \mathrm{Cl}, 2.3-15.5)^{\mathrm{a}}$ \\
\hline & & & & All-cause mortality & OR $5.4(95 \% \mathrm{Cl}, 2.4-1 \mathrm{I} .9)^{\mathrm{a}}$ \\
\hline \multirow[t]{2}{*}{ Laurent et $\mathrm{al}^{4}$} & PWV & HTs (1980) & 50 & CV mortality & OR I.5I (95\% Cl, I.08-2.II) \\
\hline & & & & All-cause mortality & OR I.34 (95\% Cl, I.04-I.74) \\
\hline Meaume et $\mathrm{al}^{5}$ & PWV & Elderly $>70$ years $(14 \mid)$ & 87 & CV mortality & OR I.I9 (95\% Cl, I.03-I.37) \\
\hline \multirow[t]{2}{*}{ Shoji et al ${ }^{6}$} & PWV & ESDR $(265)$ & 55 & CV mortality & HR I.I8 (95\% Cl, I.00-I.39) \\
\hline & & & & All-cause mortality & HR I.I6 (95\% Cl, I.03-I.29) \\
\hline Boutouyrie & PWV & HTs (I045) & 51 & $\mathrm{CHD}$ & HR $2.66(95 \% \mathrm{Cl}, \mathrm{I} .27-5.56)^{\mathrm{b}}$ \\
\hline et $\mathrm{al}^{7}$ & & & & All CV events & HR I.49 (95\% Cl, 0.82-2.7I) $)^{b}$ \\
\hline Laurent et $\mathrm{al}^{8}$ & PWV & HTs (1715) & 51 & Fatal stroke & OR I.39 (95\% Cl, I.08-I.72) \\
\hline \multirow[t]{2}{*}{ Shokawa et al ${ }^{9}$} & PWV & Hawaii-Los Angeles- & 64 & $\mathrm{CV}$ mortality & HR $4.24(95 \% \mathrm{Cl}, \mathrm{I} .39-12.96)^{\mathrm{c}}$ \\
\hline & & Hiroshima study (492) & & All-cause mortality & HR I.42 $(95 \% \mathrm{Cl}, 0.96-2.1 \mathrm{I})^{\mathrm{c}, \mathrm{d}}$ \\
\hline \multirow{3}{*}{$\begin{array}{l}\text { Willum-Hansen } \\
\text { et al }{ }^{10}\end{array}$} & PWV & General population, & 55 & Composite CVEP & HR I.I7 (95\% Cl, I.04-I.32) \\
\hline & & MONICA study (1678) & & CV mortality & HR I.20 (95\% Cl, I.0I-I.4I) \\
\hline & & & & $\mathrm{CHD}$ & HR I.I6 (95\% Cl, I.00-I.35) \\
\hline Inoue et al" & PWV & $\begin{array}{l}\text { Middle-aged and elderly } \\
\text { Japanese men (3960) }\end{array}$ & 61 & All-cause mortality & OR I.28 (95\% Cl, 0.97-I.68) \\
\hline \multirow[t]{2}{*}{ Mitchell et $\mathrm{a}^{21}$} & PWV & Framingham Heart & 63 & CV events & HR I.48 $(95 \% \mathrm{Cl}, \mathrm{I} .16-1.91)^{c}$ \\
\hline & & Study (2232) & & & \\
\hline \multirow[t]{2}{*}{ London et al ${ }^{12}$} & Al & ESRD $(180)$ & 54 & All-cause mortality & HR I.5I (95\% Cl, I.23-I.86) \\
\hline & & & & CV mortality & HR I.48 (95\% Cl, I.I6-I.90) \\
\hline Williams et $\mathrm{al}^{20}$ & Central PP & HTs, ASCOT study (2073) & 63 & $\begin{array}{l}\mathrm{CV} \text { events and } \\
\text { procedures, RI }\end{array}$ & HR I.I3 (95\% Cl, I.00-1.26) \\
\hline \multirow[t]{2}{*}{ Roman et $\mathrm{al}^{1 / 4}$} & Central PP & American Indians Strong & 64 & Fatal and nonfatal & HR I.I5 (95\% Cl, I.07-I.24) \\
\hline & & Heart Study (2403) & & CV events & \\
\hline Pini et $\mathrm{a}^{15}$ & Carotid PP & $\begin{array}{l}\text { General population } \geq 65 \\
\text { years }(398)\end{array}$ & 73 & $\mathrm{CV}$ events & HR I.23 (95\% Cl, I.10-1.37) \\
\hline Wang et $\mathrm{al}^{19}$ & Central PP & NTs, untreated HTs (I272) & 52 & CV mortality & HR I.26 (95\% Cl, I.02-I.56) \\
\hline \multirow[t]{2}{*}{ Roman et $\mathrm{al}^{1 / 4}$} & Central SBP & American Indians Strong & 64 & Fatal and nonfatal & HR I.07 (95\% Cl, I.0I-I.I4) \\
\hline & & Heart Study (2403) & & CV events & \\
\hline \multirow[t]{2}{*}{ Jankowski et al ${ }^{17}$} & Aortic PP & Patients undergoing & 57 & Fatal and nonfatal & HR I. $25(95 \% \mathrm{Cl}, \mathrm{I} .09$ to I.43) \\
\hline & & coronary angiography (I 109) & & CV events & \\
\hline Wang et al ${ }^{19}$ & Central SBP & NTs, untreated HTs (1272) & 52 & CV mortality & HR I.30 (95\% Cl, I.2I-I.5I) \\
\hline Pini et a $\left.\right|^{15}$ & Carotid SBP & $\begin{array}{l}\text { General population } \geq 65 \\
\text { years }(398)\end{array}$ & 73 & $\mathrm{CV}$ events & HR I.I9 $(95 \% \mathrm{Cl},|.08-| .31)^{c}$ \\
\hline Saladini et $\mathrm{a}^{22}$ & Central SBP & $\begin{array}{l}\text { Young untreated HTs, } \\
\text { HARVEST study (354) }\end{array}$ & 32 & $\begin{array}{l}\text { Development of } \mathrm{HT} \\
\text { needing treatment }\end{array}$ & OR $7.0(95 \% \mathrm{Cl}, \mathrm{I} .5-33.3)^{f}$ \\
\hline Grey et al ${ }^{16}$ & $\begin{array}{l}\text { Small artery } \\
\text { compliance }\end{array}$ & Outpatients (4|9) & $>19$ & $\mathrm{CV}$ events & OR I.50 (95\% Cl, I.20-I.80) \\
\hline
\end{tabular}

Notes: adjusted also for peripheral diastolic blood pressure; badjusted also for peripheral blood pressure; ${ }^{c}$ adjusted also for peripheral systolic blood pressure; ${ }^{\mathrm{a}} \mathrm{P}=0.08$; eadjusted also for peripheral pulse pressure; fadjusted also for 24-hour blood pressure.

Abbreviations: PWV, pulse wave velocity; PP, pulse pressure; Al, augmentation index; SBP, systolic blood pressure; ESRD, end-stage renal disease; HTs, hypertensive patients; CV, cardiovascular; CVEP, cardiovascular end point; NTs, normotensive subjects; RI, renal impairment; MI, myocardial infarction; CHD, coronary heart disease; $\mathrm{SD}$, sudden death; $\mathrm{CHF}$, congestive heart failure; $\mathrm{Cl}$, confidence interval; OR, odds ratio; HR, hazard ratio; MONICA, Monitoring of Trends and Determinants in Cardiovascular Disease.

the subtracted distance underestimates the travelled length, while using the direct distance, the travelled length is overestimated by $25 \% .^{28}$ This study also showed that $80 \%$ of the direct tape measure distance $(80 \% \mathrm{DD})$ is a fairly accurate estimate of the real travelled distance. Because the European Society of Hypertension guidelines propose an aortic stiffness cutoff value of $12 \mathrm{~m} / \mathrm{sec}$ based on PWV data from direct tape measure distances, using the more accurate $80 \% \mathrm{DD}$, the cutoff value should be adapted accordingly to $9.6 \mathrm{~m} / \mathrm{sec}$.
When using the subtracted distance as in the Framingham study, the cutoff value should be $8.4 \mathrm{~m} / \mathrm{sec}$. The Framingham study showed that using this cutoff value, the probability of a first major cardiovascular event within the next 8 years was about $3 \%{ }^{24}$ In the year 2010 , reference values for aortic stiffness have been published based on the $80 \%$ DD. These reference value tables also show the range from the 10th to the 90th percentile. ${ }^{29}$ This may allow investigation of whether a patient deviating from their percentile over time may be 
at higher risk and is likely to identify patients at risk much earlier. It should be noted that AI and augmentation pressure are not surrogates of arterial stiffness. Many devices claim to measure arterial stiffness. Some measure PWV of an arterial segment in mixed elastic and muscular arteries, thereby weakening their predictive value. Others use methods other than PWV and frequently are substantially confounded by other factors.

\section{Central BP}

In young subjects with elastic arterial walls, systolic BP and pulse pressure (PP) in the ascending aorta may be lower than BP measured in the upper limb by up to $20 \mathrm{mmHg}$ (Figure 1). On average, this difference is lower in the general population, and in patients with hypertension approximates 6-11 mmHg. ${ }^{30}$ The difference between central and peripheral pressure applies to the pulsatile component of BP, whereas the steady component (usually represented by MAP) does not change significantly along the arterial tree when the subject is in the recumbent position. ${ }^{31}$

Central systolic BP and PP have been shown to be correlated with the extent of coronary atherosclerosis, carotid intima-media thickness, left ventricular hypertrophy, and left ventricular diastolic function. ${ }^{32-34}$ In addition, a number of studies suggest closer correlation of end-organ damage with central BP than with peripheral BP. ${ }^{14,19,33}$ The
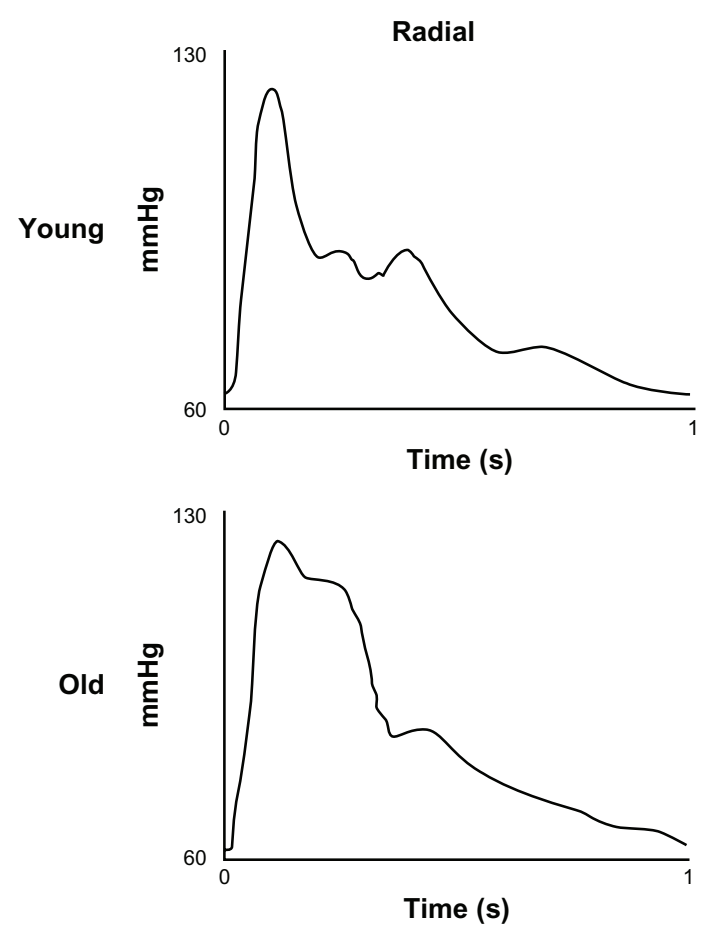

correlation between PP and coronary atherosclerosis is particularly important because most cardiovascular deaths are caused by coronary events. Although there is no doubt about the presence of a significant relationship between the pulsatile BP component and coronary atherosclerosis, this link is in fact bidirectional. ${ }^{31}$ On the one hand, diffuse atherosclerotic plaques impair the elastic properties of the arterial wall (although unstable, soft, and lipid-rich plaques do not impair arterial compliance), while on the other hand, increased stiffness enhances the pulsatile component of BP, leading to progression of atherosclerotic lesions. This leads to a vicious circle, which is difficult to prevent or break in clinical practice. Several studies have highlighted the predictive value of central BP (Table 1). In 1109 subjects followed for 4.5 years, a $10 \mathrm{mmHg}$ aortic PP increase was associated with a $13 \%$ increase in cardiovascular events. ${ }^{17}$ In addition, the pulsatile component of BP was at least as good a predictor of future cardiovascular events as left ventricular ejection fraction, the extent of coronary atherosclerosis, diabetes, and kidney function. A recent meta-analysis of five prospective studies showed a higher (with borderline significance) predictive value of central as compared with peripheral PP, although central and peripheral PP were not measured simultaneously under the same conditions in all studies included in the analysis. ${ }^{18}$ Accordingly, Wang et al showed that when central and peripheral systolic pressure were both included
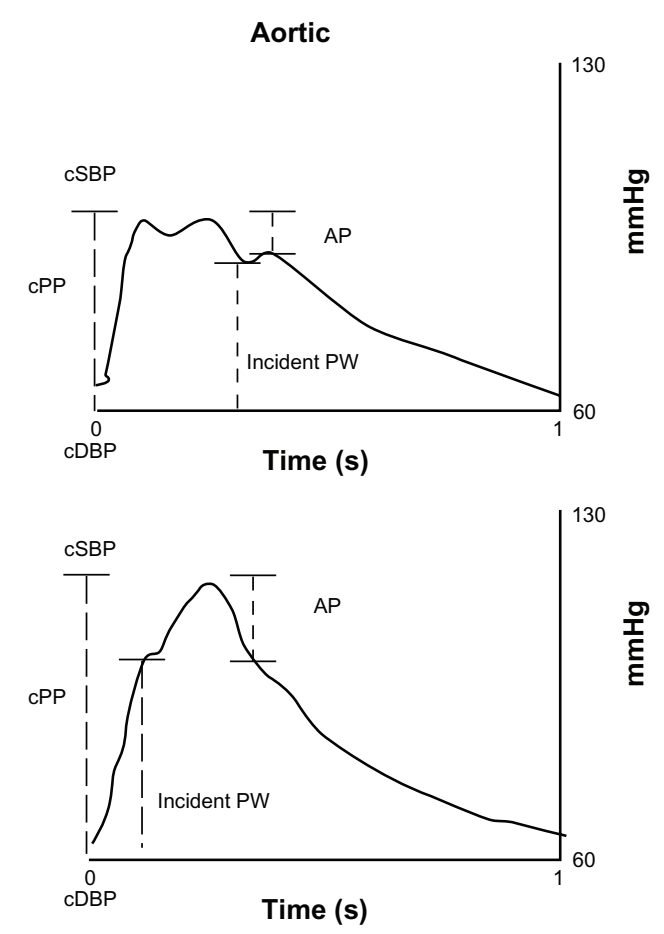

Figure I Radial (left) and aortic (right) waveforms in a young and an old subject.

Abbreviations: cSBP, central systolic blood pressure; CDBP, central diastolic blood pressure; cPP, central pulse pressure; AP, augmented pressure; PW, pulse wave. 
into a regression model, only central pressure remained significantly related to cardiovascular risk. ${ }^{19}$

Moreover, BP-lowering drugs can have differential effects on central aortic pressures and hemodynamics compared with brachial BP. According to results from the CAFÉ (Conduit Artery Function Evaluation) study, there is evidence that brachial BP is not a good surrogate for the effect of antihypertensive drugs on central arterial hemodynamics. In CAFÉ, despite a similar effect on brachial systolic BP between treatment groups, atenolol-thiazide-based treatment was much less effective than amlodipine-perindopril-based treatment in lowering central aortic pressures. ${ }^{20}$ Treatmentrelated differences in central aortic pressures may be a potential mechanism to explain the different clinical outcomes between the two treatment arms found in ASCOT (the Anglo Scandinavian Cardiac Outcomes Trial). ${ }^{34}$ At variance with these results, Mitchell et al did not find a significant association between central PP and cardiovascular risk. ${ }^{24}$ These discordant results may be caused by the difference in the studied populations or methods used for central BP assessment. Mitchell et al used applanation tonometry of the brachial artery which was criticized on the basis of the difficulties with applanation of the brachial artery against bone or ligaments, as can be done with the radial and carotid arteries. ${ }^{35}$ It is also argued that the signal is sensed through the stiff bicipital aponeurosis when applanation tonometry of the brachial artery is used. ${ }^{35}$ Another study suggested no predictive value of central BP and a high predictive value of peripheral pressure for cardiovascular events in several hundred elderly female hypertensives. ${ }^{36}$ It is well known that the difference between central and peripheral BP values is lower in females than in males and is decreasing with age. ${ }^{37}$ Thus, brachial systolic BP becomes a better surrogate of central systolic BP in older age groups, chiefly in female individuals, and this could at least partly explain these negative results. In addition, due to the low prevalence (7\%) of known vascular disease in the Dart et al hypertensive cohort, it is possible that other factors, including hypertension, were more relevant in determining outcome than vascular stiffness. $^{36}$

\section{Relationship between central BP and age}

Only a few population studies have described age-related changes in both peripheral and central systolic pressures and in pressure amplification. Age-related changes in central BP parameters were assessed in randomly recruited European subjects from FLEMENGHO (the Flemish Study on Environment, Genes and Health Outcomes, $\mathrm{n}=949$ ) and EPOGH (the European Project On Genes In Hypertension, $\mathrm{n}=858) .{ }^{38}$ Participants on antihypertensive treatment were excluded, leaving 1420 subjects for cross-sectional analysis of baseline data. For the longitudinal analyses, 398 subjects were available with a median follow-up of 4.8 years. PWV was obtained from applanation tonometry at the radial artery using a SphygmoCor ${ }^{\circledR}$ device. Central systolic BP was the maximum pressure of the central waveform. Systolic augmentation was calculated by subtracting the first peak shoulder from systolic BP. Pressure amplification was defined as peripheral minus central systolic BP. In line with several previously published cross-sectional population studies, cross-sectional analyses showed that both peripheral and central systolic BP increased significantly with age, and with steeper slopes in women than in men. The age-related increase in central systolic BP assessed cross-sectionally was larger than that in peripheral systolic BP in both women and men. The pressure amplification decreased with age to the same extent in both genders. The slopes of peripheral and central systolic augmentation pressure were steeper in women than in men. Moreover, in women $(<20$ years versus $40-50$ years) as well as in men (30-40 years versus 60-70 years), central systolic augmentation occurred at a younger age than peripheral systolic augmentation. In the longitudinal analyses in the subsample of 208 women and 190 men, all changes in peripheral and central systolic BP were significant from baseline to follow-up. However, women had a greater pressure amplification than men. The slopes on age for the peripheral and central pressures were similar at baseline and follow-up. Age-related increases in peripheral and central systolic BP were consistently greater in the longitudinal as compared with cross-sectional assessment. Recently, Bia et al studied age-related structural and functional vascular parameter profiles in 388 healthy Uruguayan subjects. ${ }^{39}$ In this sample, they found the expected age-related changes in systolic and diastolic pressure for both central (aortic) and peripheral (radial) pressure levels, with a decrease in the centre-periphery systolic amplification. Both central and peripheral systolic pressure variations showed a steeper increase beyond the sixth decade of life. In agreement with previous work, beyond that age, the centerperiphery systolic amplification remained constant. ${ }^{40} \mathrm{PWV}$ in this population showed a $0.12 \mathrm{~m} / \mathrm{sec}$ increase per year that was comparable with that found by other authors in nonhypertensive subjects. ${ }^{29}$ Echo Doppler analysis of the carotid arteries showed an age-related increase in intima-media thickness in both the left and right common carotid arteries 
of $0.008 \mathrm{~mm} /$ year beyond the third decade of life, and an increase in both the systolic and diastolic vascular diameters with a parallel reduction of circumferential stress with age. The data from the above studies indicate that peripheral systolic pressure approximates central pressure with aging (Figure 1). This might explain why peripheral systolic BP becomes the main predictor of cardiovascular complications in older subjects.

\section{Central BP and systolic hypertension in the young}

A controversial issue still debated in the literature is the pathogenesis and clinical significance of isolated systolic hypertension (ISH) in young subjects. Two main hypotheses have been forwarded to explain ISH in the young. According to McEniery et al, ISH in young subjects may be caused by increased stroke volume, early aortic stiffness, or by a combination of these two mechanisms. ${ }^{41}$ At variance with this hypothesis, some authors claim that ISH in youth is "spurious hypertension," a benign condition due to exaggerated PP amplification at peripheral sites while central BP is normal. ${ }^{42,43}$ In HARVEST (the Hypertension and Ambulatory Recording VEnetia STudy), 64 subjects with ISH were examined and compared with 287 subjects with systolic-diastolic hypertension, and with 34 normotensive subjects. ${ }^{22}$ ISH subjects were divided into two subgroups according to whether central systolic BP was below or above the median in the group $(120.5 \mathrm{mmHg})$. Arterial compliance was impaired in ISH subjects with high central BP, while in ISH subjects with low central BP it was similar to that in normotensives. In addition, total peripheral resistance was increased in ISH subjects with high central systolic BP, and was normal in those with low central pressure. During a median follow-up of 9.5 years, hypertension requiring treatment was developed by $60 \%$ of subjects with systolicdiastolic hypertension ( $P=0.022$ versus normotensives) and by $50 \%$ of ISH subjects with high central systolic BP ( $P=0.041$ versus normotensives), while in ISH subjects with low central pressure, the rate of hypertension was similar to that observed in normotensives (15.1\% and $14.7 \%$, respectively), ${ }^{22}$ as shown in Figure 2.

A limitation to the applicability of central BP assessment in clinical practice may be the lack of normal limits in young-to-middle-aged individuals, because of the paucity of longitudinal data in this segment of the population. Hulsen et $\mathrm{al}^{43}$ used the 90th percentile score in 750 adults aged 26-31 years to define the maximum allowed

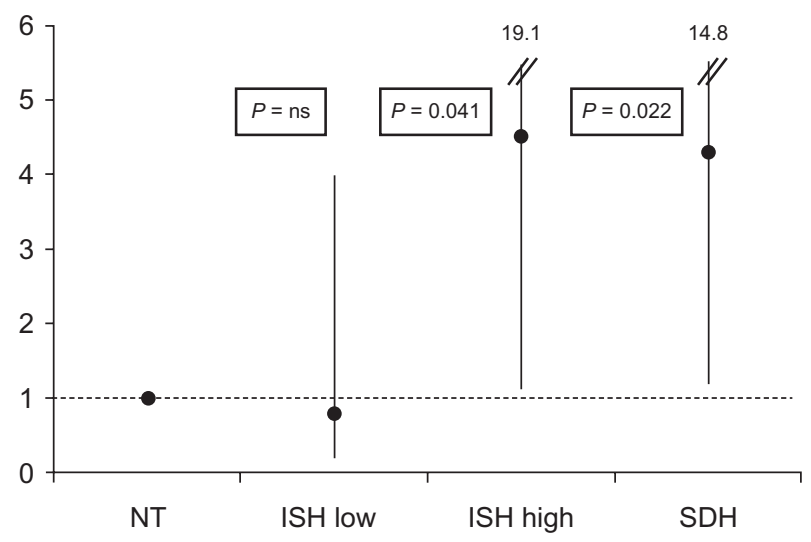

Figure 2 Odds ratios and confidence intervals for development of hypertension needing antihypertensive treatment from a multivariable logistic regression.

Notes: Odds ratios represent risk of hypertension for the three groups of hypertensive versus normotensive subjects; $P$ values are adjusted for age, gender, body mass index, parental hypertension, physical activity, smoking, coffee, alcohol, body mass index change, follow-up duration, average 24-hour systolic blood pressure, diastolic blood pressure, and heart rate. Data from Saladini et al. ${ }^{22}$

Abbreviations: NT, normotensives; ISH low, isolated systolic hypertensives with low central systolic blood pressure; ISH high, isolated systolic hypertensives with high central systolic blood pressure; SDH, systolic-diastolic hypertensives.

central systolic BP. Using this approach, spurious systolic hypertension in individuals with ISH was defined as a central systolic BP less than $124 \mathrm{mmHg}$ for men and less than $120 \mathrm{mmHg}$ for women. In a smaller study performed in normotensive individuals, O'Rourke et $\mathrm{al}^{43}$ identified the $126 \mathrm{mmHg}$ level as the upper normal limit for central systolic BP. Based on the results from HARVEST, $120 \mathrm{mmHg}$ may be regarded as the approximate threshold value for identifying ISH individuals with true normal central systolic BP, because below this partition value, the risk of hypertension was shown to be close to that of normotensive individuals. ${ }^{22}$ According to the HARVEST results, the $125 \mathrm{mmHg}$ cutoff level may be used to identify truly hypertensive patients. ${ }^{22}$

\section{Methodological issues}

Although central BP has achieved much attention in recent years for the assessment of cardiovascular risk, it should be pointed out that there are still methodological problems with its non invasive measurement. This is attested to by the results of a recent study that demonstrated considerable differences between central pressure estimates obtained with the Omron ${ }^{\circledR}$ and the SphygmoCor device, due to algorithm differences. ${ }^{44}$ Central systolic BP estimates obtained with the two devices correlated strongly $(r=0.99)$, but the Omron estimate was $18.8 \mathrm{mmHg}$ higher than the SphygmoCor estimate.

Central BP measured invasively cannot be used in everyday clinical practice and we must rely on noninvasive 
techniques. There are five methods that hold promise for noninvasive central BP determination (Table 2), ie, applanation tonometry of the radial artery, applanation tonometry of the carotid artery, the secondary systolic wave method, oscillometric method, and the N-point moving average method. The N-point moving average method, as well as the oscillometric method, allows for 24-hour central systolic pressure monitoring. ${ }^{45}$ One should be aware that using any of the above methods, the predicted central BP values are distorted by the error related to noninvasive measurement of brachial BP. ${ }^{46}$ Recently, the use of diameter distension waveforms instead of applanation tonometry was also suggested. ${ }^{47}$

Taking into account all the available evidence, it seems too early to recommend replacement of peripheral BP with central BP measurement in everyday clinical practice. Before such a recommendation can be made, several conditions should be fulfilled, ie: the high accuracy and reliability of central pressure measurements should be shown beyond any doubt; the higher predictive value of central pressure for cardiovascular events as compared with peripheral pressure should be proved in various patient subsets; the measurement of central pressure should be inexpensive, easy, and not time-consuming; and central BP should be a better surrogate for the effect of antihypertensive drugs on cardiovascular outcomes compared with peripheral BP. For the time being, central BP measurement and assessment of arterial stiffness and compliance parameters can be considered useful adjuncts to clinic and ambulatory brachial BP measurements for better assessment of cardiovascular risk.

\section{Clinical significance of arterial distensibility in young to middle-aged subjects}

The association of age with various arterial distensibility parameters has been described extensively in the literature. However, little is known about the clinical significance of arterial distensibility assessment in young subjects. O'Rourke et al observed a progressive increase in carotidfemoral PWV with aging, that started in childhood, while no association with age was found for the muscular upper limb arteries. ${ }^{43}$ In a cross-sectional study involving the general population, Janner et al reported a curvilinear increase in AI with age, that had already started at the age of 20 years. ${ }^{48}$ For large artery (C1) and small artery (C2) compliance, assessed with the HDI device, in a population of healthy normotensive subjects of normal weight, Gardner and Parker observed a progressive increase in compliance with aging, in both the large and small arteries, until the age of 20-25 years, and then a progressive decline. ${ }^{49}$ In HARVEST, arterial distensibility assessment was performed in a sample of subjects aged 20-55 years. ${ }^{50}$ In this study, a progressive decline in $\mathrm{C} 1$ and $\mathrm{C} 2$ starting from the age of 20 years was seen, with a negative correlation that was stronger for $\mathrm{C} 2(\mathrm{r}=-0.41$, $P=0.001)$ than for $\mathrm{C} 1(\mathrm{r}=-0.13, P=0.03)$. Measures of arterial stiffness also showed a progressive increase with age.

Table 2 Noninvasive methods of central blood pressure measurement

\begin{tabular}{|c|c|c|c|}
\hline Method & Device & Principle & Sources of errors \\
\hline $\begin{array}{l}\text { Applanation tonometry } \\
\text { of radial artery }\end{array}$ & Eg, SphygmoCor ${ }^{\circledR}$ & $\begin{array}{l}\text { Central systolic pressure is calculated } \\
\text { using transfer function from calibrated } \\
\text { radial pulse }\end{array}$ & $\begin{array}{l}\text { Noninvasive measurement of brachial BP* } \\
\text { Calibration of radial pulse with brachial } \\
\text { pressure }\end{array}$ \\
\hline $\begin{array}{l}\text { Applanation tonometry } \\
\text { of carotid artery }\end{array}$ & $\begin{array}{l}\text { Eg, Complior }{ }^{\circledR}, \\
\text { SphygmoCor }\end{array}$ & $\begin{array}{l}\text { Carotid pulse wave is calibrated } \\
\text { with brachial pressure }\end{array}$ & $\begin{array}{l}\text { Noninvasive measurement of brachial BP* } \\
\text { Difference between diastolic and mean } \\
\text { pressure in carotid and brachial artery } \\
\text { Difference between BP in carotid artery } \\
\text { and ascending aorta }\end{array}$ \\
\hline Oscillometric method & $\begin{array}{l}\text { Eg, arteriograph, } \\
\text { BPLabVasotens }{ }^{\circledR}\end{array}$ & $\begin{array}{l}\text { Calculation of central systolic pressure } \\
\text { is based on late systolic wave amplitude } \\
\text { Calibration of brachial pressure wave } \\
\text { with brachial pressure }\end{array}$ & Noninvasive measurement of brachial BP* \\
\hline $\begin{array}{l}\text { Secondary systolic wave } \\
\text { in radial pulse }\end{array}$ & $\begin{array}{l}\text { Eg, SphygmoCor, } \\
\text { Omron HEM- } 9000^{\circledR}\end{array}$ & $\begin{array}{l}\text { Second systolic peak in applanated } \\
\text { radial pulse approximate central } \\
\text { systolic pressure }\end{array}$ & $\begin{array}{l}\text { Noninvasive measurement of brachial BP* } \\
\text { Calibration of radial pulse with brachial } \\
\text { pressure }\end{array}$ \\
\hline $\begin{array}{l}\mathrm{N} \text {-point moving average } \\
\text { method }\end{array}$ & BPro $^{\circledR}$ & Moving average acts as a low pass filter & Noninvasive measurement of brachial BP* \\
\hline
\end{tabular}

Note: $*$ When the radial arterial pulses are calibrated with brachial cuff pressures, calibration errors are transferred to the predicted values.

Abbreviation: BP, blood pressure. 
The correlation was stronger for AI $(\mathrm{r}=0.46 P<0.001)$ than for PWV $(r=0.26 P<0.001)$. HARVEST showed that arterial distensibility may already be impaired in the early stage of hypertension. ${ }^{50}$ Compared with a group of normotensive subjects used as controls, hypertensive participants showed a lower $\mathrm{C} 1(14.6 \pm 4.6 \mathrm{~mL} / \mathrm{mmHg} \times 10$ in the latter and $17.0 \pm 4.7 \mathrm{~mL} / \mathrm{mmHg} \times 10$ in the former, $P=0.002$, adjusted for age, gender, height, and heart rate) and $\mathrm{C} 2(6.6 \pm 2.8 \mathrm{~mL} / \mathrm{mmHg} \times 100$ and $8.0 \pm 3.8 \mathrm{~mL} / \mathrm{mmHg} \times 100$, respectively, $P<0.001)$. The hypertensive participants also showed a higher PWV $(9.0 \pm 3.1 \mathrm{~m} / \mathrm{sec}$ versus $7.9 \pm 1.3 \mathrm{~m} / \mathrm{sec}$ ), even if the difference did not reach the level of statistical significance, and a greater AI $(16.5 \% \pm 0.25 \%$ versus $1.3 \% \pm 0.2 \%$, adjusted $P=0.046$ ). Another interesting finding of this study was that arterial compliance was impaired also in the subset of participants with white coat hypertension. ${ }^{51}$ Both sustained and white coat hypertensives showed a lower $\mathrm{C} 1$ and $\mathrm{C} 2$ compared with normotensive controls, without significant differences between the two hypertensive subgroups.

The above data indicate that, in young to middle-aged individuals, arterial distensibility assessment is helpful for identifying subjects at higher risk who may need early pharmacological treatment. In these individuals, the measurement of central BP is a useful adjunct to clinical and 24-hour BP assessment, especially in subjects with ISH. As mentioned above, ISH individuals with low central BP have a lower risk of hypertension needing treatment than those with high central BP. ${ }^{22}$ However, the lack of reference values for the different arterial distensibility indexes in the young limits their applicability in clinical practice. Further prospective studies that relate arterial distensibility parameters to cardiovascular events and mortality in young to middle-aged subjects are needed.

\section{Hypertension and arterial stiffness in old age}

Epidemiology has shown that the increase in BP with age begins from the very first weeks of life. ${ }^{51}$ Later, there is a progressive and graded increase of both systolic and diastolic BP during adolescence and adult life, while after the age of 60-65 years, only the systolic component increases and the diastolic remains stable or even decreases. While diastolic values only increase until the age of 60-65 years, systolic values constantly increase, although with a different slope, progressively increasing PP. The arbitrary cutoff of $140 \mathrm{mmHg}$ is often exceeded, leading to a high prevalence of ISH in the elderly. The age-related BP increase during childhood and adolescence is mainly due to an increase in cardiac function and peripheral resistance, whereas during the rest of life it is due to progressive reduction of arterial compliance and to aortic calcification..$^{51,52}$

A stiff aorta has increased impedance and does not dilate well under pressure, leading stroke volume to impact directly on the arterioles. This produces early arterial wave reflection. As a consequence, the reflected wave that falls within the diastolic phase of the cardiac cycle in young people, in the elderly tends to move into the systolic phase. This causes an increase in systolic BP and a parallel decrease in diastolic values. This process, involving the onset of sympathetic overactivity, is progressive and very slow, and early wave reflection represents its final stage. Nevertheless, it should be pointed out that the increase in systolic BP with age is a general population phenomenon, not necessarily applicable to the individual subject. The "echogenetic context" 53 is the reason why some subjects remain normotensive in advanced age. The phenotype "systolic BP" is the result not only of a mosaic of genes but also of a mosaic of environmental factors (Table 3). ${ }^{54-61}$

These factors, accounting for the wide variability of prevalence and incidence of hypertension around the world, act not only at the global level but also at a very local level. In the district of Lugalawa (Tanzania), subjects who are used to eating fish show a lower BP and no increase in systolic BP with increasing age in comparison with those of the same genetic strain living some kilometers away and eating a more complex diet. ${ }^{56}$ In Europe too, important differences were found in the prevalence of hypertension in a survey representative of the general population recruited from

Table 3 Factors associated with unequal distribution of blood pressure levels

Ethnic differences, genetics, and racial selection ${ }^{\mathrm{a}}$

Sodium intake ${ }^{\mathrm{b}}$ ( $\uparrow$ intake leading to $\uparrow \mathrm{BP}$ in genetically determined sodium-sensitive subjects)

Intake of meat and vegetables ${ }^{\mathrm{b}}$ ( $\uparrow$ meat/vegetable ratio leading to $\uparrow \mathrm{BP}$ )

Social stress ${ }^{\mathrm{b}}$ ( $\downarrow$ stress leading to $\downarrow$ BP and to lack of $\uparrow$ BP with age)

Culture $^{c}(\downarrow$ culture leading to $\uparrow \mathrm{BP}$ )

Income ${ }^{c}(\downarrow$ income leading to $\uparrow$ BP)

Industrialization ( $\uparrow$ industrialization leading to $\uparrow \mathrm{BP}$ )

Altitude $^{\mathrm{d}}$ ( $\uparrow$ altitude leading to $\uparrow \mathrm{BP}$ )

Temperature thermal excursion ${ }^{\mathrm{de} e}(\uparrow$ temperature leading to $\uparrow \mathrm{BP})$

Water pollution ${ }^{\dagger}$ (lead, cadmium)

Air particulate ${ }^{g}$ ( $\uparrow$ particulate leading to $\uparrow \mathrm{BP}$ )

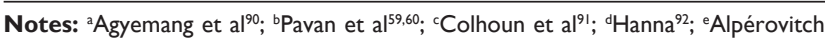
et al ${ }^{93}$; 'Sharp et al ${ }^{94}$; 8 Sun et al..$^{95}$

Abbreviation: $\mathrm{BP}$, blood pressure. 
eight countries. ${ }^{62}$ Therefore, environmental factors play a role in allowing full expression of the genetic potential of individuals to become hypertensive with age, and the BP increase with age should be seen as a sort of adaptation to the environment.

\section{Pulse pressure as a risk factor}

After the age of 60-65 years, an increase in systolic BP with a decrease or no change in diastolic BP produces a progressive increase of PP. ${ }^{63,64}$ This increase, which was once considered nothing more than a normal characteristic of the elderly, is currently seen as a possible marker of endothelial dysfunction. PP is the simplest measure of large arterial stiffening and pulse hypertension, and is a better predictor of cardiovascular outcomes than systolic hypertension ${ }^{63,64}$ (Figure 3).

Darne et al were among the first researchers to demonstrate that the pulsatile BP component is related to cardiovascular outcome. ${ }^{65}$ However, their seminal results were difficult to interpret and impossible to implement in everyday clinical practice. ${ }^{65}$ First, calculation of the pulsatile and steady components required application of complex formulae obtained by use of principal component analysis of data coming from just one population. Second, the physiologic meaning of the obtained indices was difficult to interpret.

Between 2000 and 2002, based on data from longstanding epidemiologic studies and data obtained in the framework of large-scale clinical trials on hypertension,

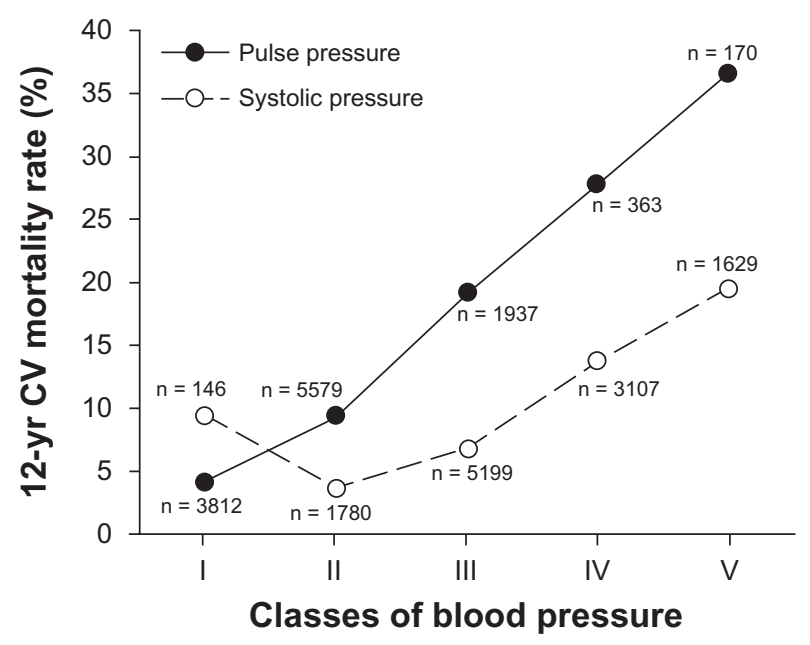

Figure 3 Trend of 12-year cardiovascular (CV) mortality rate in relation to pulse pressure and systolic pressure.

Notes: Classes are $<50,50-75,75-100,100-125$, and $>125 \mathrm{mmHg}$ for pulse pressure, and $<100,100-125,125-150,150-175$, and $>175 \mathrm{mmHg}$ for systolic pressure; the slope of pulse pressure is steeper and more linear than that of systolic pressure, that shows a J-shaped trend; data from II,86I men and women aged I8-95 years from four Italian general populations. . $^{54,55,61,62,64}$ many researchers approached the question of whether PP (the physiologic pulsatile component of BP) or MAP, the (physiologic steady component of BP) is more closely related to cardiovascular outcome.

Blacher et al meta-analyzed individual patient data from three large-scale clinical trials, ie, EWPHE (European Working Party on High Blood Pressure in the Elderly), Syst-Eur (Systolic Hypertension in Europe), and Syst-China (Systolic Hypertension in China), all performed in elderly hypertensives. ${ }^{66}$ In this population of 7929 patients mostly affected with ISH, they were able to demonstrate that $\mathrm{PP}$ and not MAP is related to cardiovascular outcomes. A $10 \mathrm{mmHg}$ wider PP, after adjustment for MAP and other possible confounders, was associated with a $15 \%$ (95\% confidence interval $[\mathrm{CI}] 7-22, P<0.001)$ greater risk of total mortality, a $22 \%(95 \%$ CI 13-33, $P<0.001)$ greater risk of cardiovascular mortality, a $17 \%$ (95\% CI 10-24) greater risk of fatal and nonfatal stroke, and a 13\% (95\% CI 2-24, $P<0.05)$ greater risk of fatal and nonfatal coronary events. MAP was not associated with an increase in risk for any of the studied outcomes. ${ }^{66}$

Staessen et al analyzed individual data for 15,693 patients aged 60 years or older with ISH who had been enrolled in eight clinical trials of hypertension, ie, SHEP (Systolic Hypertension in the Elderly Program), Syst-Eur, Syst-China, EWPHE, HEP (Hypertension Evaluation Project), STOP1 (Swedish Trial in Old Patients with hypertension), MRC1 (Medical Research Council trial of treatment of mild hypertension), and MRC2 (Medical Research Council trial of treatment of hypertension in older adults). ${ }^{67}$ The principal aim of this analysis was to demonstrate that treatment of ISH in elderly patients with systolic $\mathrm{BP} \geq 160 \mathrm{mmHg}$ and diastolic $\mathrm{BP}<95 \mathrm{mmHg}$ reduces the incidence of cardiovascular complications. In an analysis stratified by level of PP at entry, in the subgroup with PP in the range of $65-89 \mathrm{mmHg}$, 119 patients (95\% CI 102-143) had to be treated for 5 years to prevent one death of cardiovascular origin, and 75 patients (95\% CI 68-84) to prevent one coronary event, while the corresponding numbers in the subgroup with $\mathrm{PP} \geq 90 \mathrm{mmHg}$ were 63 (95\% CI 58-70) and 57 (95\% CI 53-62), for cardiovascular mortality and coronary events, respectively. ${ }^{67}$ In an analysis restricted to 7757 patients who had been enrolled into the control groups of eight trials, $10 \mathrm{mmHg}$ higher systolic BP was associated with 14\% (95\% CI 7-21) greater risk of all-cause mortality, while a $5 \mathrm{mmHg}$ higher diastolic $\mathrm{BP}$ was associated with a 4\% $(95 \%$ CI 0-8) decrease in risk of all-cause mortality, thus stressing the role of PP as a risk factor for mortality $(P=0.05)$. Based on individual data for 
17,239 patients who were enrolled into control groups of seven randomized control trials (SHEP, Syst-Eur, MRC1, MRC2, HEP, EWPHE, STOP1), Gąsowski et al extended the results of the aforementioned analysis to patients of relatively younger age. ${ }^{68}$ The median age of the group was 62.7 (range $26.3-97.0,25 \%$ of patients $<50$ ) years. Overall, a $10 \mathrm{mmHg}$ wider PP at baseline was associated with a $6 \%$ (95\% CI 3-10, $P=0.001$ ) higher risk of all-cause mortality, a $7 \%(95 \%$ CI 1-13, $P=0.01)$ higher risk of cardiovascular mortality, and a 7\% (95\% CI 1-15, $P=0.03)$ higher risk of coronary mortality, but not with risk of fatal stroke. In similar analyses, MAP was not associated with risk of mortality. The PP-age interaction was significant for fatal stroke $(P=0.04)$. A $10 \mathrm{mmHg}$ wider PP was associated with a 29\% lower risk of fatal stroke in patients aged $<56$ years, a $13 \%$ higher risk of fatal stroke in patients aged 56-68 years, and a 16\% higher risk of fatal stroke in patients aged $>68$ years. The interaction between MAP and age was significant for fatal coronary heart disease $(P=0.01)$. A $5 \mathrm{mmHg}$ higher MAP was associated with a $10 \%$ higher risk of fatal coronary disease in patients aged $<56$ years, an $8 \%$ higher risk of coronary disease in patients aged 56-68 years, and a 3\% lower risk of fatal coronary disease in those aged $>68$ years. ${ }^{68}$

$\mathrm{PP}$ is related to adverse cardiovascular outcome independent of other BP components. Although this is especially true of older patients with ISH, the relationship, in the case of fatal outcomes, seems to hold true in populations where large proportions of patients are $<50$ years, although for some outcomes, MAP gains predictive significance at younger ages. The role of PP is not limited to classic cardiovascular outcomes. It has been demonstrated, that in pregnant women with hypertension developing in the third trimester, 24-hour ambulatory PP is an independent predictor of preterm delivery and small body weight at birth. ${ }^{69}$ Widening PP may therefore be more predictive of cardiac risk than either systolic or diastolic BP considered separately. Therefore, it has been proposed that high PP might be part of the Framingham cardiovascular risk score. ${ }^{70}$

\section{Relationship between sympathetic nervous system activity and arterial function}

There is growing evidence that both sympathetic overactivity $^{71,72}$ and arterial stiffening ${ }^{73}$ are implicated in the development of hypertension and its complications. Increased adrenergic activity in patients with hypertension is supported by various lines of evidence, including measurements of heart rate and catecholamine levels, and data obtained using microneurography. Potential mechanisms leading to increased sympathetic activity in hypertension may be divided into two major categories, ie, increased adrenergic activity resulting from disturbed peripheral regulatory mechanisms such as arterial baroreceptors, cardiopulmonary mechanoreceptors, and chemoreceptors, and a primary increase of sympathetic activity within the central nervous system. These abnormal mechanisms, either peripheral or central, are likely related to both genetic and environmental factors. Studies using regional catecholamine spillover techniques showed increased noradrenaline release in the central nervous system in patients with hypertension. ${ }^{74}$ This involved mainly subcortical regions, such as those responsible for emotional responses. The sympathetic nervous system may thus constitute an important link between mental stress and hypertension. This concept is based on the following findings: persistent sympathetic nervous stimulation is commonly present in hypertensives; suprabulbar projections of noradrenergic brainstem neurons are activated; and adrenaline is released as a cotransmitter in sympathetic nerves. With a better understanding of the role of the sympathetic nervous system, a rational background for more effective treatment of hypertension and better prevention of cardiovascular events has been established. Of note, adrenergic activation is a hallmark of not only hypertension, but also metabolic syndrome, obstructive sleep apnea, congestive heart failure, and chronic kidney disease. Thus, it appears that activation of the adrenergic system may be a common pathogenetic mechanism in these conditions.

The level of sympathetic nervous activity may determine properties of large arteries. Removal of adrenergic tone by anesthesia of the brachial plexus and the spinal cord results in markedly increased distensibility of the radial artery and femoral artery, respectively. ${ }^{75}$ Short-term sympathetic activation is able to decrease radial arterial compliance. The reduction in arterial compliance probably results from complex interactions between changes in distending BP and changes in radial arterial smooth muscle tone. Interestingly, pathological states characterized by sympathetic nervous system activation (congestive heart failure, renal failure, and obstructive sleep apnea) are associated with artery stiffness. Furthermore, cigarette smoking, which has a powerful sympathetic excitatory effect, is associated with impairment of large artery function and increased aortic stiffness. ${ }^{76}$ These changes are reversible with smoking cessation. Finally, there is growing evidence that tachycardia, a reliable marker of high sympathetic tone and cardiovascular risk, ${ }^{77}$ is an important determinant of arterial function and PWV. ${ }^{23}$ 
Swierblewska et al have recently shown that sympathetic activity is an independent determinant of PWV and diastolic function in normal humans. ${ }^{78}$ Data from HARVEST are in agreement with those results. ${ }^{79}$ In the participants divided according to whether they had sympathetic predominance or normal autonomic nervous system activity, assessed by spectral analysis of heart rate variability performed in the lying position, on standing or during a mental stress, subjects with sympathetic predominance exhibited impaired $\mathrm{C} 1$ and $\mathrm{C} 2$ compared with subjects with normal activity of the autonomic nervous system. ${ }^{79}$ The link between autonomic nervous system activity and arterial stiffness might reflect a direct effect of sympathetic discharge on vasomotor tone. ${ }^{80,81}$ However, other mechanisms might be implicated. First, the sympathetic nervous system promotes endothelial dysfunction, growth of vascular muscle and associated fibrosis, ie, structural changes of the arterial wall, playing a role per se in the increase in arterial stiffness, independently of BP. Second, the sympathetic nervous system may contribute to arterial stiffness by its effects on the renin-angiotensin aldosterone system, promoting arterial wall fibrosis. Third, increased sympathetic activity and consequent loss of large vessel elasticity might facilitate transmission of pressor stress into the resistant vessels and microvasculature. In addition, resetting of the baroreflex by both sympathetic overactivity and structural changes might further facilitate target organ damage.

In conclusion, sympathetic overactivity is implicated in the stiffening of large arteries and diastolic dysfunction, and thereby might contribute to development and progression of hypertension and its complications. Along with more standard measures, such as heart rate and BP, sympathetic activity should also be taken into account in interpreting and understanding measures of arterial function.

\section{Interactive effect of genetics and salt intake on arterial properties}

Another important determinant of the properties of the elastic arteries is salt intake. As mentioned above, hypertension arises through the complex interaction between genetic, environmental, and lifestyle factors. More than 150 candidate genes have been studied in relation to hypertension and other cardiovascular phenotypes. ${ }^{82}$ Often, strong associations are reported that are not confirmed in subsequent studies. However, a negative finding or a minor genetic effect in a general population may become a major genetic effect in the presence of a particular environmental background. This relationship has been explored within the frame of EPOGH, a European family-based epidemiological survey ${ }^{83}$ The aim of EPOGH is to investigate the interactions between genes and environment in the pathogenesis of hypertension and related intermediate phenotypes, focusing on the relationship between genes encoding various components of the renin-angiotensinaldosterone system and the adducin cytoskeleton, and sodium excretion as an index of salt intake. The hypothesis of effect modification of the aforementioned genes by sodium intake was made a priori because renin-angiotensin-aldosterone system and adducin play a key role in sodium homeostasis and, via various mechanisms, high sodium might affect BP and sympathetic tone, promote cardiac growth and change wall properties of the large arteries. Angiotensin II and aldosterone generated by the angiotensin-converting enzyme and aldosterone synthase, respectively, not only regulate sodium and water homeostasis, but also influence vascular remodeling in response to high BP. In $622 \mathrm{EPOGH}$ subjects from three European populations, Wojciechowska et al investigated whether the angiotensin-converting enzyme D/I and cytochrome P450 (CYP)11B2 C-344T polymorphisms influence arterial wave reflections, a measure of vascular stiffness. ${ }^{83}$ The peripheral and central AIs were significantly higher in CYP11B2-344C allele carriers than in CYP11B2-344T homozygotes in population-based and family-based analyses. However, this effect of the CYP11B2 polymorphism only occurred in subjects with a higher than median urinary sodium excretion $(210 \mathrm{mmol} / \mathrm{day})$. The association between systolic augmentation and the angiotensin-converting enzyme D/I polymorphism did not reach statistical significance. ${ }^{83}$ Previous studies demonstrated that a high salt intake in humans is associated with increased arterial stiffness and vascular hypertrophy. ${ }^{84}$ Furthermore, stroke-prone spontaneously hypertensive rats fed $0.9 \% \mathrm{NaCl}$ in drinking water, compared with a control group given tap water, had increased expression of mRNA for CYP11B2 in the arterial wall, but lower levels of circulating aldosterone. ${ }^{85}$ Thus, an excessive salt intake might contribute to increased arterial stiffness by inappropriately sustaining expression of the CYP11B2 gene in the arterial wall, especially in CYP11B2-344C allele carriers. Adducin is a membrane skeleton protein consisting of $\alpha$ - and $\beta$ - or $\alpha$ - and $\gamma$-subunits. Mutations in $\alpha$ - and $\beta$-adducin are associated with hypertension. In the framework of the EPOGH study, Cwynar et al investigated whether polymorphisms in the genes encoding $\alpha$-adducin (Gly460Trp), $\beta$-adducin (C1797T), and $\gamma$-adducin (A386G), alone or in combination, affected PP, an index of vascular stiffness. ${ }^{86}$ Peripheral and central PP were measured by conventional sphygmomanometry and applanation tonometry, respectively. Among carriers of the $\alpha$-adducin 
Trp allele, peripheral and central PP were 5.8 and $4.7 \mathrm{mmHg}$ higher, respectively, in $\gamma$-adducin GG homozygotes than in their AA counterparts, due to an increase in systolic pressure. $\gamma$-adducin GG homozygosity was associated with a lower urinary $\mathrm{Na}^{+} / \mathrm{K}^{+}$ratio among $\alpha$-adducin Trp allele carriers and with a higher urinary aldosterone excretion among $\alpha$-adducin GlyGly homozygotes. Sensitivity analyses in founders and offspring separately, and tests based on the transmission of the $\gamma$-adducin $\mathrm{G}$ allele across families, confirmed interaction between the $\alpha$-adducin and $\gamma$-adducin genes. ${ }^{86}$ Previous observations demonstrated that, in the population at large, the plasma concentration of endogenous ouabain, a steroid hormone released from the adrenal gland and possibly from the hypothalamus, increases with the number of mutated $\alpha$-adducin Trp alleles. ${ }^{87}$ At very low concentrations within the nanomolar range, endogenous ouabain may enlarge the membrane pool of active sodium pumps and activate mediators of cell growth. ${ }^{87}$ To what extent the aforementioned pathways might increase PP, either via renally mediated effects on circulating plasma volume and cardiac output, or via structural or functional alterations in the vasculature, must be further clarified. The EPOGH demonstrated that individuals with the same genetic predisposition had different vascular stiffness depending on whether they ate a high-sodium or a low-sodium diet. As demonstrated by the present results, environmental factors modify the actions of genes. Thus, population studies that take into account geneenvironment and gene-gene interactions will increasingly be used to study complex cardiovascular phenotypes.

\section{Conclusion}

Arterial stiffness is a well recognized predictor of cardiovascular morbidity and mortality. However, the large number of parameters used to define arterial stiffness and the differing modalities used to assess aortic mechanics have somewhat hampered the current clinical impact of these measures. Carotid-femoral PWV is the most validated method used to quantify arterial stiffness noninvasively and is considered today the gold standard index, given its strong prediction of cardiovascular events and mortality. The AI and central BP reflect different facets of the pathophysiological abnormalities underlying functional vascular damage because both central arterial stiffness and peripheral reflectance are important determinants of these parameters. The main problem with these derived parameters is calculation by means of a transfer function, which has only been validated in selected patient groups. In addition, the independent predictive value of central hemodynamics in primary prevention remains to be determined. It has been hypothesized that the high prognostic predictive value of PWV could be due to its reflecting the cumulative damage of cardiovascular risk factors on the arterial wall over long periods, whereas central hemodynamics can fluctuate over time, and a sporadic measurement may not reflect their long-term impact on the arterial wall. On the other hand, each of the above mentioned parameters reflects a different characteristic of the atherosclerotic process, involving functional and/or morphological changes in the vessel wall. Therefore, acquiring simultaneous measurements of different parameters of vascular function and structure could theoretically enhance the power to improve risk stratification. According to McEniery et al, the AI might be a more sensitive marker of arterial alteration and cardiovascular risk in younger individuals, whereas the aortic PWV is likely to be a better measure in older individuals. ${ }^{88}$ However, whether pulse wave analysis can equally predict different end-organ damage has to be elucidated. Further studies are needed to compare the usefulness of each of these parameters among different populations of subjects with differing clinical characteristics.

Since the pioneering and revolutionary approach of Struś to measurement of the pulse, many conceptual and technical achievements have been obtained in the area of arterial hemodynamics. Continuous technological effort is necessary to refine our methods of investigation in order to detect early arterial abnormalities. Arterial stiffness and its consequences represent the great challenge of the twentyfirst century for affluent countries, and "de-stiffening" will be the goal of the next decades. As demonstrated by a number of controlled trials, the separate reduction of systolic and diastolic BP is able to reduce major cardiovascular events significantly, not only in the elderly but also in the very old. ${ }^{89}$ However, it is possible that an excess reduction of diastolic BP accounts for the not completely satisfactory results sometimes observed with antihypertensive treatment, particularly on coronary mortality. Unfortunately, selective reduction of systolic rather than diastolic BP is a difficult target. Lifestyle measures reproducing the conditions spontaneously present in emergent countries, such as healthy diet, increase of physical activity, and reduction of stress, should be taken into consideration as possible destiffening measures in addition to drugs.

\section{Acknowledgment}

On June 16, 2011, at the satellite meeting to the XXI Meeting of the European Society of Hypertension "Arterial elasticity in hypertension - historical perspectives and recent 
advances," a group of European experts held a workshop on recent advances in the field of arterial elasticity. A major interest of the symposium was to celebrate the 500th anniversary of the birth of the precursor of modern cardiology, the Polish physician Josephus Struthius Polonus (Józef Struś, 1510-1568) who began his career at the University of Padua in Italy. This article summarizes many individual contributions made at the symposium and deals with a wide range of subjects, focusing especially on the pathophysiology and clinical significance of high central BP.

\section{Disclosure}

The authors report no conflicts of interest in this work.

\section{References}

1. Grzybowski A, Sak J, Pawlikowski J. 500th anniversary of the birth of the precursor of modern cardiology: Josephus Struthius Polonus (1510-1568). Cardiol J. 2011;18(5):581-586.

2. Parker KH. A brief history of arterial wave mechanics. Med Biol Eng Comput. 2009;47(2):111-118.

3. Blacher J, Guerin AP, Pannier B, et al. Impact of aortic stiffness on survival in end-stage renal disease. Circulation. 1999;99(18):2434-2439.

4. Laurent S, Boutouyrie P, Asmar R, et al. Aortic stiffness is an independent predictor of all-cause and cardiovascular mortality in hypertensive patients. Hypertension. 2001;37(5):1236-1241.

5. Meaume S, Benetos A, Henry OF, et al. Aortic pulse wave velocity predicts cardiovascular mortality in subjects $>70$ years of age. Arterioscler Thromb Vasc Biol. 2001;21(12):2046-2050.

6. Shoji T, Emoto M, Shinohara K, et al. Diabetes mellitus, aortic stiffness, and cardiovascular mortality in end-stage renal disease. J Am Soc Nephrol. 2001;12(10):2117-2124.

7. Boutouyrie P, Tropeano AI, Asmar R, et al. Aortic stiffness is an independent predictor of primary coronary events in hypertensive patients a longitudinal study. Hypertension. 2002;39(1):10-15.

8. Laurent S, Katsahian S, Fassot C, et al. Aortic stiffness is an independent predictor of fatal stroke in essential hypertension. Stroke. 2003;34(5):1203-1206.

9. Shokawa T, Imazu M, Yamamoto H, et al. Pulse wave velocity predicts cardiovascular mortality: findings from the Hawaii-Los AngelesHiroshima study. Circ J. 2005;69(3):259-264.

10. Willum-Hansen T, Staessen JA, Torp-Pedersen C, et al. Prognostic value of aortic pulse wave velocity as index of arterial stiffness in the general population. Circulation. 2006;113(5):664-670.

11. Inoue $\mathrm{N}$, Maeda $\mathrm{R}$, Kawakami $\mathrm{H}$, et al. Aortic pulse wave velocity predicts cardiovascular mortality in middle-age and elderly Japanese men. Circ J. 2009;73(3):549-553.

12. London GM, Blacher J, Pannier B, et al. Arterial wave reflections and survival in end-stage renal failure. Hypertension. 2001;38(3):434-438.

13. Covic A, Mardare N, Gusbeth-Tatomir P, et al. Arterial wave reflections and mortality in haemodialysis patients - only relevant in elderly, cardiovascularly compromised? Nephrol Dial Transplant. 2006;21(10): 2859-2866.

14. Roman MJ, Devereux RB, Kizer JR, et al. Central pressure more strongly relates to vascular disease and outcome than does brachial pressure: the Strong Heart Study. Hypertension. 2007;50(1):197-203.

15. Pini R, Cavallini MC, Palmieri V, et al. Central but not brachial blood pressure predicts cardiovascular events in an unselected geriatric population: the ICARe Dicomano Study. J Am Coll Cardiol. 2008;51(25):2432-2439.

16. Grey E, Bratteli C, Glasser SP, et al. Reduced small artery but not large artery elasticity is an independent risk marker for cardiovascular events. Am J Hypertens. 2003;16(4):265-269.
17. Jankowski P, Kawecka-Jaszcz K, Czarnecka D, et al. Pulsatile but not steady component of blood pressure predicts cardiovascular events in coronary patients. Hypertension. 2008;51(4):848-855.

18. Vlachopoulos C, Aznaouridis K, O’Rourke MF, Safar ME, Baou K, Stefanadis C. Prediction of cardiovascular events and all-cause mortality with central haemodynamics: a systematic review and meta-analysis. Eur Heart J. 2010;31(15):1865-1871.

19. Wang KL, Cheng HM, Chuang SY, et al. Central or peripheral systolic or pulse pressure: which best relates to target organs and future mortality? J Hypertens. 2009;27(3):461-467.

20. Williams B, Lacy PS, Thom SM, et al; CAFE Investigators. Differential impact of blood pressure-lowering drugs on central aortic pressure and clinical outcomes: principal results of the Conduit Artery Function Evaluation (CAFE) study. Circulation. 2006;113(9):1213-1225.

21. Mitchell GF, Hwang SJ, Vasan RS, et al; Arterial stiffness and cardiovascular events: the Framingham Heart Study. Circulation. 2010; 121(11):505-511.

22. Saladini F, Santonastaso M, Mos L, et al; HARVEST Study Group. Isolated systolic hypertension of young-to-middle-age individuals implies a relatively low risk of developing hypertension needing treatment when central blood pressure is low. J Hypertens. 2011;29(7):1311-1319.

23. Laurent S, Cockcroft J, Van Bortel L, et al; European Network for Noninvasive Investigation of Large Arteries. Expert consensus document on arterial stiffness: methodological issues and clinical applications. Eur Heart J. 2006;27(21):2588-2605.

24. Mitchell GF, Wang N, Palmisano JN, et al. Hemodynamic correlates of blood pressure across the adult age spectrum: noninvasive evaluation in the Framingham Heart Study. Circulation. 2010;122(14): 1379-1386.

25. Mancia G, De Backer G, Dominiczak A, et al. The task force for the management of arterial hypertension of the European Society of Hypertension, The task force for the management of arterial hypertension of the European Society of Cardiology. 2007 Guidelines for the management of arterial hypertension: The Task Force for the Management of Arterial Hypertension of the European Society of Hypertension $(\mathrm{ESH})$ and of the European Society of Cardiology (ESC). Eur Heart J. 2007;28(12):1462-1536.

26. Van Bortel LM, Duprez D, Starmans-Kool MJ, et al. Clinical applications of arterial stiffness, Task Force III: recommendations for user procedures. Am J Hypertens. 2002;15(5):445-452.

27. Vermeersch SJ, Rietzschel ER, De Buyzere ML, et al. Distance measurements for the assessment of carotid to femoral pulse wave velocity. J Hypertens. 2009;27(12):2377-2385.

28. Huybrechts SA, Devos DG, Vermeersch SJ, et al. Carotid to femoral pulse wave velocity: a comparison of real travelled aortic path lengths determined by MRI and superficial measurements. J Hypertens. 2011;29(8):1577-1582.

29. Reference Values for Arterial Stiffness' Collaboration. Determinants of pulse wave velocity in healthy people and in the presence of cardiovascular risk factors: 'establishing normal and reference values'. Eur Heart J. 2010;31(19):2338-2350.

30. Safar ME, Blacher J, Protogerou A, Achimastos A. Arterial stiffness and central hemodynamics in treated hypertensive subjects according to brachial blood pressure classification. J Hypertens. 2008;26(1):130-137.

31. Safar ME, Blacher J, Jankowski P. Arterial stiffness, pulse pressure, and cardiovascular disease-Is it possible to break the vicious circle? Atherosclerosis. 2011;218(2):263-271.

32. Jankowski P, Kawecka-Jaszcz K, Czarnecka D, et al. Ascending aortic, but not brachial blood pressure-derived indices are related to coronary atherosclerosis. Atherosclerosis. 2004;176(1):151-155.

33. Roman MJ, Okin PM, Kizer JR, et al. Relations of central and brachial blood pressure to left ventricular hypertrophy and geometry: the Strong Heart Study. J Hypertens. 2010;28(2):384-388.

34. Ostergren J, Poulter NR, Sever PS, et al; ASCOT investigators The Anglo-Scandinavian Cardiac Outcomes Trial: blood pressurelowering limb: effects in patients with type II diabetes. $J$ Hypertens. 2008;26(11):2103-2111. 
35. O'Rourke MF, Safar ME, Roman MJ. Letter by O'Rourke et al; regarding article, "Arterial stiffness and cardiovascular events: the Framingham Heart Study." Circulation. 2010;122(19):e512.

36. Dart AM, Gatzka CD, Kingwell BA, et al. Brachial blood pressure but not carotid arterial waveforms predict cardiovascular events in elderly female hypertensives. Hypertension. 2006;47(4):785-790.

37. Safar ME, Jankowski P. Central blood pressure and hypertension: role in cardiovascular risk assessment. Clin Sci (Lond). 2009;116(4):273-282.

38. Wojciechowska W, Stolarz-Skrzypek K, Tikhonoff V, et al; On Behalf Of The European Project On Genes In Hypertension (Epogh) Investigators. Age dependency of central and peripheral systolic blood pressures: Cross-sectional and longitudinal observations in European populations. Blood Pressure. 2011. [Epub ahead of print.]

39. Bia D, Zócalo Y, Farro I, et al. Integrated evaluation of age-related changes in structural and functional vascular parameters used to assess arterial aging, sub-clinical atherosclerosis and cardiovascular risk in Uruguayan adults: CUiiDARTE Project. Int J Hypertens. 2011. [Epub ahead of print.]

40. Avolio A. Central aortic blood pressure and cardiovascular risk: a paradigm shift? Hypertension. 2008;51(6):1470-1471.

41. McEniery CM, Yasmin, Wallace S, et al. Increased stroke volume and aortic stiffness contribute to isolated systolic hypertension in young adults. Hypertension. 2005;46(1):221-226.

42. O'Rourke MF, Vlachopoulos C, Graham RM. Spurious systolic hypertension in youth. Vasc Med. 2000;5(3):141-145.

43. Hulsen HT, Nijdam ME, Bos WJ, et al. Spurious systolic hypertension in young adults; prevalence of high brachial systolic blood pressure and low central pressure and its determinants. $J$ Hypertens. 2006;24(6): $1027-1032$.

44. Kips JG, Schutte AE, Vermeersch SJ, et al. Comparison of central pressure estimates obtained from SphygmoCor, Omron HEM9000AI and carotid applanation tonometry. J Hypertens. 2011;29(6): 1115-1120.

45. Jankowski P, Bednarek A, Olszanecka A, Windak A, Czarnecka D, Kawecka-Jaszcz K. Analysis of twenty-four-hour central blood pressure profile - a feasibility study. J Hypertens. 2011;29(e-suppl A):e178.

46. Smulyan H, Safar ME. Blood pressure measurement: retrospective and prospective views. Am J Hypertens. 2011;24(6):628-634.

47. Kips J, Vanmolkot F, Mahieu D, et al. The use of diameter distension waveforms as an alternative for tonometric pressure to assess carotid blood pressure. Physiol Meas. 2010;31(4):543-553.

48. Janner JH, Godtfredsen NS, Ladelund S, Vestbo J, Prescott E. Aortic augmentation index: reference values in a large unselected population by means of the SphygmoCor device. Am J Hypertens. 2010; 23(2):180-185.

49. Gardner AW, Parker DE. Association between arterial compliance and age participants 9 to 77 years old. Angiology. 2010;61(1):37-41.

50. Longo D, Zaetta V, Perkovic D, et al. Impaired arterial elasticity in young patients with white-coat hypertension. Blood Press Monit. 2006;11(5):243-249.

51. Casiglia E, Tikhonoff V, Mazza A, Pessina AC. Systolic and pulse hypertension. Aging Health. 2005;1(1):85-94.

52. Elliott RJ, McGrath LT. Calcification of the human thoracic aorta during aging. Calcif Tissue Int. 1994;54(4):268-273.

53. Kuznetsova T, Staessen JA, ReinekeT, et al. Context - dependency of the relation between left ventricular mass and AGT gene variants. J Hum Hypertens. 2005;19(2):155-163.

54. Casiglia E, Tikhonoff V, Mazza A, et al. C-344T polymorphis of the aldosterone synthase gene and blood pressure in the elderly: a population-based study. J Hypertens. 2005;23(11):1991-1996.

55. Tikhonoff V, Kuznetsova T, Stolarz K, et al. Blood pressure phenotypes in relation to the beta-adducin $\mathrm{C} 1797 \mathrm{~T}$ polymorphism in the European Project on Genes in Hypertension (EPOGH). Blood Press Monit. 2003; 8(4):151-154.

56. Pauletto P, Puato M, Caroli MG, et al. Blood pressure and atherogenic lipoprotein profiles of fish-diet and vegetarian villagers in Tanzania: the Lugalawa study. Lancet. 1996;348(9030):784-788.
57. Moser M, Harris M, Pugatch D, Ferber A, Gordon B. Epidemiology of hypertension. II. Studies of blood pressure in Liberia. Am J Cardiol. 1962;10(1):424-431.

58. Timio M, Lippi G, Venanzi S, et al. Blood pressure trend and cardiovascular events in nuns in a secluded order: a 30-year follow-up study. Blood Press. 1997;6(2):81-87.

59. Pavan L, Casiglia E, Pauletto P, et al. Blood pressure, serum cholesterol and nutritional state in Tanzania and in the Amazon: comparison with an Italian population. J Hypertens. 1997;15(10):1083-1090.

60. Pavan L, Casiglia E, Braga LM, et al. Effects of a traditional lifestyle on the cardiovascular risk profile: the Amondava population of the Brazilian Amazon. Comparison with matched African, Italian and Polish populations. J Hypertens. 1999;17(6):749-756.

61. Casiglia E, Tikhonoff V, Caffi S, et al. Effects of the C825T polymorphism of the GNB3 gene on body adiposity and blood pressure in fertile and menopausal women: a population-based study. J Hypertens. 2008;26(2):238-243.

62. Kuznetsova T, Staessen JA, Kawecka-Jaszcs J, et al. Quality control of the blood pressure phenotype in the European Project on Genes in Hypertension. Blood Press Monit. 2002;7(4):251-224.

63. Casiglia E, Tikhonoff V, Mazza A, Scarpa R, Piccoli A, Pessina AC. Pulse pressure and coronary mortality in elderly men and women from general population. J Hum Hypertens. 2002;16(3):611-620.

64. Mazza A, Pessina AC, Privato G, Tikhonoff V, Pavei A, Casiglia E. Pulse pressure: an independent predictor of coronary and stroke mortality in elderly females from the general population. Blood Pressure. 2001;10(2):205-211.

65. Darne B, Girerd X, Safar M, Cambien F, Guize L. Pulsatile versus steady component of blood pressure: a cross-sectional analysis and a prospective analysis on cardiovascular mortality. Hypertension. 1989;13(4):392-400.

66. Blacher J, Staessen JA, Girerd X, et al. Pulse pressure not mean pressure determines cardiovascular risk in older hypertensive patients. Arch Intern Med. 2000;160(8):1085-1089.

67. Staessen JA, Gąsowski J, Wang JG, et al. Risks of untreated and treated isolated systolic hypertension in the elderly: meta-analysis of outcome trials. Lancet. 2000;355(9207):865-872.

68. Gąsowski J, Fagard RH, Staessen JA, et al. Pulsatile blood pressure component as predictor of mortality in hypertension: a metaanalysis of clinical trial control groups. J Hypertens. 2002;20(1): 145-151.

69. Liro M, Gąsowski J, Wydra D, Grodzicki T, Emerich J, Narkiewicz K. Twenty-four-hour and conventional blood pressure components and risk of preterm delivery or neonatal complications in gestational hypertension. Blood Press. 2009;18(1-2):36-43.

70. Nawrot TS, Staessen JA, Thijs L, et al. Should pulse pressure become part of the Framingham risk score? J Hum Hypertens. 2004;18(4):279-286

71. Esler M, Lambert G, Brunner-La Rocca HP, Vaddadi G, Kaye D. Sympathetic nerve activity and neurotransmitter release in humans: translation from pathophysiology into clinical practice. Acta Physiologica Scandinavica. 2003;177(3):275-284.

72. Grassi G. Assessment of sympathetic cardiovascular drive in human hypertension: achievements and perspectives. Hypertension. 2009;54(4):690-697.

73. Laurent S, Boutouyrie P. Recent advances in arterial stiffness and wave reflection in human hypertension. Hypertension. 2007;49(6): 1202-1206.

74. Ferrier C, Esler MD, Eisenhofer G, et al. Increased norepinephrine spillover into the jugular veins in essential hypertension. Hypertension. 1992;19(1):62-69.

75. Failla M, Grappiolo A, Emanuelli G, et al. Sympathetic tone restrains arterial distensibility of healthy and atherosclerotic subjects. J Hypertens. 1999;17(8):1117-1124.

76. Jatoi NA, Jerrard-Dunne P, Feely J, Mahmud A. Impact of smoking and smoking cessation on arterial stiffness and aortic wave reflection in hypertension. Hypertension. 2007;49(5):981-985. 
77. Palatini P, Benetos A, Grassi G, et al; European Society of Hypertension. Identification and management of the hypertensive patient with elevated heart rate: statement of a European Society of Hypertension Consensus Meeting. J Hypertens. 2006;24(4):603-610.

78. Swierblewska E, Hering D, Kara T, et al. An independent relationship between muscle sympathetic nerve activity and pulse wave velocity in normal humans. J Hypertens. 2010;28(5):979-984.

79. Palatini P, Longo D, Zaetta V, Perkovic D, Garbellotto R, Pessina AC. Evolution of blood pressure and cholesterol in stage 1 hypertension role of autonomic nervous system activity. J Hypertens. 2006;24(7): 1375-1381.

80. Delius W, Wallin G, Hagbarth KE. Role of sympathetic nerve impulses in regulation of peripheral circulation. Scand J Clin Lab Invest Suppl. 1973;128(1):47-50.

81. Joyner MJ, Charkoudian N, Wallin BG. Sympathetic nervous system and blood pressure in humans: individualized patterns of regulation and their implications. Hypertension. 2010;56(1):10-16.

82. Sartori M, Semplicini A, Siffert W, et al. G-protein beta3-subunit gene $825 \mathrm{~T}$ allele and hypertension: a longitudinal study in young grade I hypertensives. Hypertension. 2003;42(5):909-914.

83. Wojciechowska W, Staessen JA, Stolarz K, et al. Association of peripheral and central arterial wave reflections with the CYP11B2-344C allele and sodium excretion. J Hypertens. 2004;22(12):2311-2319.

84. Safar ME, Thuilliez C, Richard V, Benetos A. Pressure-independent contribution of sodium to large artery structure and function in hypertension. Cardiovasc Res. 2000;46(2):269-276.

85. Takeda Y. Pathophysiological roles of vascular 11 beta-hydroxysteroid dehydrogenase and aldosterone. J Steroid Biochem Mol Biol. 2003;7(85):443-447.
86. Cwynar M, Staessen JA, Tichá M, et al. Epistatic interaction between alpha- and gamma-adducin influences peripheral and central pulse pressures in white Europeans. J Hypertens. 2005;23(5):961-969.

87. Wang JG, Staessen JA, Messaggio E, et al. Salt, endogenous ouabain and blood pressure interactions in the general population. J Hypertens. 2003;21(8):1475-1481.

88. McEniery CM, Yasmin, Hall IR, et al; ACCT Investigators. Normal vascular aging: differential effects on wave reflection and aortic pulse wave velocity: the Anglo-Cardiff Collaborative Trial (ACCT). J Am Coll Cardiol. 2005;46(9):1753-1760.

89. Gueyffier F, Bulpitt C, Boissel JP, et al. Antihypertensive drugs and very old people: a subgroup meta-analysis of randomised controlled trials. Lancet. 1999;353(9155):793-796.

90. Agyemang C, Kunst A, Bhopal R, et al. A cross-national comparative study of bloodpressure and hypertension between English and Dutch South-Asian- and African-origin populations: the role of national context. Am J Hypertens. 2010;23(6):639-648.

91. Colhoun HM, Hemingway H, Poulter NR. Socio-economic status and blood pressure: an overview analysis. J Hum Hypertens. 1998;1(2):91-110.

92. Hanna JM. Climate, altitude, and blood pressure. Hum Biol. 1999;71(4):553-582.

93. Alpérovitch A, Lacombe JM, Hanon O, et al. Relationship between blood pressure and outdoor temperature in a large sample of elderly individuals: the Three-City study. Arch Intern Med. 2009;169(1):75-80.

94. Sharp DS, Becker CE, Smith AH. Chronic low-level lead exposure. Its role in the pathogenesis of hypertension. Med Toxicol. 1987;2(3):210-232.

95. Sun Q, Hong X, Wold LE. Cardiovascular effects of ambient particulate airpollution exposure. Circulation. 2010;121(25):2755-2765.
Vascular Health and Risk Management

\section{Publish your work in this journal}

Vascular Health and Risk Management is an international, peerreviewed journal of therapeutics and risk management, focusing on concise rapid reporting of clinical studies on the processes involved in the maintenance of vascular health; the monitoring, prevention and treatment of vascular disease and its sequelae; and the involvement of

\section{Dovepress}

metabolic disorders, particularly diabetes. This journal is indexed on PubMed Central and MedLine. The manuscript management system is completely online and includes a very quick and fair peer-review system, which is all easy to use. Visit http://www.dovepress.com/ testimonials.php to read real quotes from published authors. 